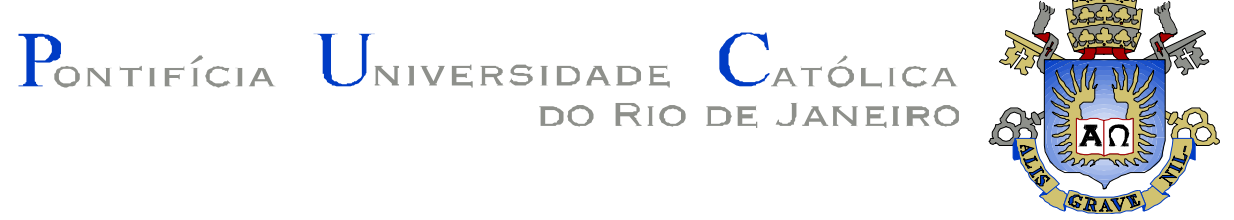

Suely de Almeida Batista Dessandre

\title{
A educação moral possível: o conflito como estratégia para a autonomia
}

Dissertação apresentada como requisito parcial para obtenção do grau de Mestre pelo Programa de Pós-graduação em Psicologia Clínica do Departamento de Psicologia da PUC-Rio

Orientadora: Maria Helena Novaes Mira 


\section{Pontifícia Universidade C atólica $_{\text {a }}$

\section{Suely de Almeida Batista Dessandre}

\section{"A educação moral possível: o conflito como estratégia para a autonomia"}

Dissertação apresentada como requisito parcial para obtenção do grau de Mestre pelo Programa de Pós-Graduação em Psicologia Clínica do Departamento de Psicologia do Centro de Teologia e Ciências Humanas da PUC-Rio. Aprovada pela Comissão Examinadora abaixo assinada.

Profa . Maria Helena Novaes Mira

Orientadora

Departamento de Psicologia - PUC-Rio

Profa. Andréa Seixas Magalhães

Departamento de Psicologia - PUC-Rio

Profa. Vera Maria Ramos de Vasconcellos Instituto de Psicologia - UFF

Prof. Paulo Fernando Carneiro de Andrade Coordenador Setorial de Pós-Graduação e Pesquisa do Centro de Teologia e Ciências Humanas - PUC-Rio

Rio de Janeiro, 27 / Janeiro /2004 
Todos os direitos reservados. É proibida a reprodução total ou parcial do trabalho sem autorização da universidade, da autora e do orientador.

\section{Suely de Almeida Batista Dessandre}

Graduou-se em Psicologia na Universidade Federal Fluminense, em 2001 e Licenciou-se em Psicologia, em 2002. É membro do Núcleo Multidisciplinar de Pesquisa, Extensão e Estudo da Criança de 0-6 anos, tendo como espaço referência a Creche-UFF, pesquisando os processos pessoais de desenvolvimento, da criança e do educador, nos espaços coletivos. Participou de pesquisas sobre o papel das concepções, crenças e valores dos educadores de creches particulares do município de Niterói. Autora de diversos trabalhos em congressos nacionais e internacionais na área de psicologia e educação, apresentando trabalhos na Jean Piaget Society, e na Sociedade Brasileira de Psicologia de Desenvolvimento, em 2001, 2002 e 2003. Membro da Sociedade Brasileira de Psicologia.

Ficha Catalográfica

Dessandre, Suely de Almeida Batista

A educação moral possível: o conflito como estratégia para a autonomia / Suely de Almeida Batista Dessandre; orientadora: Maria Helena Novaes Mira. Rio de Janeiro: PUC, Departamento de Psicologia, 2004.

123 f.;30 cm

Dissertação (mestrado) - Pontifícia Universidade Católica do Rio de Janeiro, Departamento de Psicologia.

Inclui referências bibliográficas.

1. Psicologia - Teses. 2. Psicanálise infantil 3. Conflito. 4. Educação moral e cívica. 5. Crianças Desenvolvimento. I. Mira, Maria Helena Novaes. II. Pontifícia Universidade Católica do Rio de Janeiro. 
A todas as crianças, fáceis, difíceis, agitadas, alegres e felizes, como toda criança deve ser 


\section{Agradecimentos}

À minha orientadora Professora Maria Helena Novaes Mira, doutora em criatividade e doçura, pelo prazer da convivência.

À CAPES e à PUC-Rio, pelos auxílios concedidos, sem os quais este trabalho não poderia ter sido realizado.

Às minhas amigas e parceiras de pesquisa da Universidade Federal Fluminense, em especial à $\operatorname{Prof}^{\mathrm{a}} \operatorname{Dr}^{\mathrm{a}}$ Adelaide Dias (pesquisadora da $1^{\mathrm{a}}$. Etapa).

À minha amiga Flávia, pelos momentos partilhados de incentivo e força.

À minha mestra, de hoje e de sempre, Vera Maria Ramos de Vasconcellos, pelos caminhos apontados.

Aos meus colegas da PUC-Rio, em especial à Mariângela e Célia, pela cumplicidade e pelos cafezinhos das tardes de orientação.

Aos professores que participaram da Comissão Examinadora.

A todos os professores e funcionários do Departamento pelos ensinamentos e pela ajuda.

À minha família, e todos os amigos, pelo auxílio e estímulo.

À Fundação Municipal de Educação de Niterói pelo suporte oferecido, sem o qual não seria possível o trabalho de campo.

A todos os professores que participaram do trabalho de campo, pela entrevista e acolhida.

À Cecília Fiorotti, supervisora de vida e de esperança. 


\section{Resumo}

Dessandre, Suely de Almeida Batista. A educação moral possível: o conflito como estratégia para a autonomia. Rio de Janeiro, 2003. 90 p. Dissertação de Mestrado - Departamento de Psicologia, Pontifícia Universidade Católica do Rio de Janeiro.

"A educação moral possível: o conflito como estratégia para a autonomia" é um estudo follow-up realizado com 15 crianças consideradas fáceis ou difíceis, aos 5 e 11 anos, por diferentes professores, na creche e no ensino fundamental, visando analisar as concepções destes sobre autonomia e suas estratégias, situando o conceito fácil/difícil em questões de gênero, comportamentos social/individual, além das habilidades relacionadas ao contexto escolar. Partiu-se do pressuposto que o conflito desempenha, sobretudo na dinâmica da criança difícil, um fator propulsor para a construção da personalidade moral. As 15 crianças, hoje préadolescentes, foram localizadas estudando em escolas municipais ou estaduais da rede pública do ensino fundamental da cidade de Niterói. Constatou-se que a maioria dos professores de ambos os níveis concebem autonomia como "capacidade de agir sozinho", considerando o diálogo como sua estratégia principal. O professor do ensino fundamental, ao falar de seu aluno préadolescente, refere-se a um sujeito da aprendizagem, sem enxergar o mundo das relações. Para ele, a criança é autônoma fora da escola, mas não dá conta do que lhe é esperado.

\section{Palavras-chave}

Criança fácil/difícil, conflito, autonomia, educação moral, temas transversais. 


\section{Abstract}

Dessandre, Suely de Almeida Batista. The possible moral education: the conflict as a strategy for the autonomy. Rio de Janeiro, 2003. $90 \mathrm{p}$. Dissertation - Departamento de Psicologia, Pontifícia Universidade Católica do Rio de Janeiro.

"The possible moral education: the conflict as a strategy for the autonomy" is a follow-up study, carried out with 15 considered as easy/difficult children, firstly with 5 years old at pre-school and latter on with 11 years old at basic education school (different teachers). The purpose is to analyze teacher's conception about autonomy and its strategy, focusing the concept of easy/difficult, regarding gender, social/individual behavior and school abilities. It was assumed that conflict, mainly on difficult children, is a propelling factor for the construction of the moral self. Presently, the fifteen children have been studying in public schools (municipal or state ones) at basic education level, in the Niteroi city. It was concluded that the majority of the teachers at both levels (pre-school and basic school) see autonomy as "ability to act by himself", considering the dialogue as main strategy. The teachers of basic school, when referring to his pre-adolescent pupils, see them as learning subject, forgetting the complex of people relations. However, children were not considered as "difficult" for lacking of learning capacity, but for an incompatible behavior faced to a good learning progress.

\section{Keywords}

Easy/difficult child, conflict, autonomy, moral education, transversal subjects 


\section{Sumário}

Introdução.

10

1. A educação é possível na pós-modernidade? ..............................16

1.1. Educação é dever da família. Que papel resta à escola?..............18

1.2. Especialistas da psicologia na educação....................................22

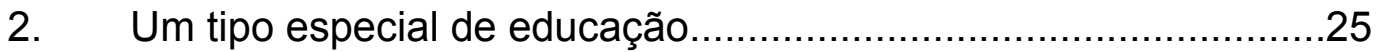

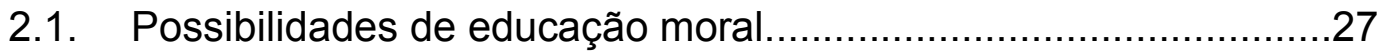

2.2. O conflito na construção da autonomia moral...............................33

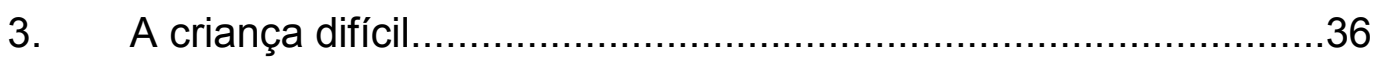

3.1. (Des)construindo a criança difícil................................................

3.2. Os sentidos da (in)disciplina.....................................................

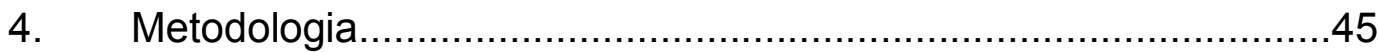

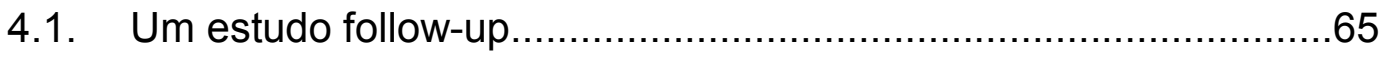

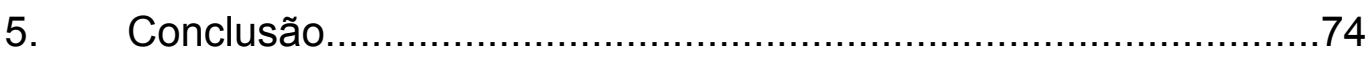

6. Referências bibliográficas...................................................

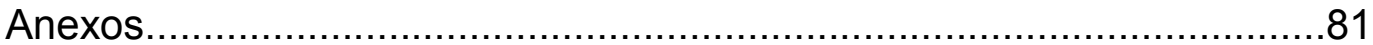


"Só ajuda o aluno a crescer o educador que se propõe a crescer também; só ensina alguma coisa aquele que está aberto para aprender, e só educa verdadeiramente quem vê diante de si uma trajetória de realizações criativas, buscando sempre se renovar, demonstrando o seu profundo respeito pelo outro e pela própria vida"

Maria Helena Novaes Mira 